\title{
A Giant Postlarva and Young of Bothid Flatfish, with Notes on the Species of Genus Bothus in Japanese Water
}

\author{
By Katsuzo Kuronuma \\ (With two figures and a plate)
}

The writer has lately had occasion to identify and study one larval and 8 young fishes, referred to the genus Bothus (Heterosomata), taken from the Pacific coast of Honshyu, Japan. One enormously large postlarva, collected near the surface of the sea off Misaki, is very thin, papery and almost transparent showing the characteristic features of the genus; the one specimen, apparently just finished the metamorphosis and taken alive at Hamana-ko, had beautiful red pigmentation on the nearly transparent body. This red pigmentation was noticed by European ichthyologists many years ago on the species of Atlantic Ocean, but has never been recorded for the Indo-Pacific form.

In the present paper there are given firstly the description of specimens and secondarily the identification of each specimen, which was done separately on genus and species.

The writer wishes to acknowledge his indebtedness to Dr. Kei Eri, Director of the Misaki Marine Biological Station, who allowed him to study the remarkable postlarva, and to Messrs. Kiyomatsu Matsubara and Reizo Seishi who submitted some of the specimens to his study.

\section{DESCRIPTION}

1. Postlarva of Bothus bleekerl Steindachner
The giant postlarva flatfish in Plate measures $61 \mathrm{~mm}$. to the caudal base. It was collected near the surface of the sea off Misaki, Kanagawa-ken by a fisherman, and was kindly handed to the writer by Dr. KeI ErI. The date of collection is November 13, 1936. Unfortunately tbe specimen, probably due to unkind handling of fisherman, was slightly mutilated on the abdomen which perhaps resulted the loss of pelvic fins.

D 93 ; A. 78 ; P. ? ; pores in lateral line 98 ; vertebrae $10+32=42$, counting the median ural plates as the last; myotomes about 41.

The flat fish, remarkable for the immense size which it has retained as a postlarva, has symmetrical eyes. The right eye locates slighly above the left but does not advance; the left eye is a little popped-out (by preservation?) and directed slightly outwards. There is a round depression, of nearly same size as the eye, just above the well developed bony-ridge which forms the upper wall of the orbit. This depression is supposed to receive the right eye which penetrates through the tissue beneath the dorfal fin. The mouth is oblique with the upper jaw extending below the front margin of the eye. The small teeth are conical and weak, arranged in a series on each jaw, the size of teeth being very variable. The nostrils 
on the left, locating just in iront of the an- behind the eye. The 3 spines are symmetrically terior rim of the bony orbit, are both surrounded developed on the head, giving a characteristic by a low dermal flap, the anterior one dirceting feature to the fish. The lower prong of the forvards. Those on the right locate almost in urohyal is triangular with rough serration along the symmetrical position with the left oncs, the free margin. The extemal margin of the but they are smaller than the latter, the anterior releithrum, ridged out of the surfare of the one is possessed by a small dermal flay, on its body, has rough serration in front of the peeposterior margin, but the posterior is a simple toral fin. The gill-rakers, represented by small round opening. There are 3 short but promi- tubcrulations, are counted 4 on the lower nent spincs arranged in a semivertical series, limb of the first arch.

the uppermost locating on the postcrulorsal corner of the brain-case, the midalle on the level of the upper margin of the eye, and the lowermost, much smaller than others, occurring

The pelvic boncs are formed by two bony up-bent hars cach with a cartilagenous triangular process ncar the middle of the bar, the left one slightly advancing the other. The two

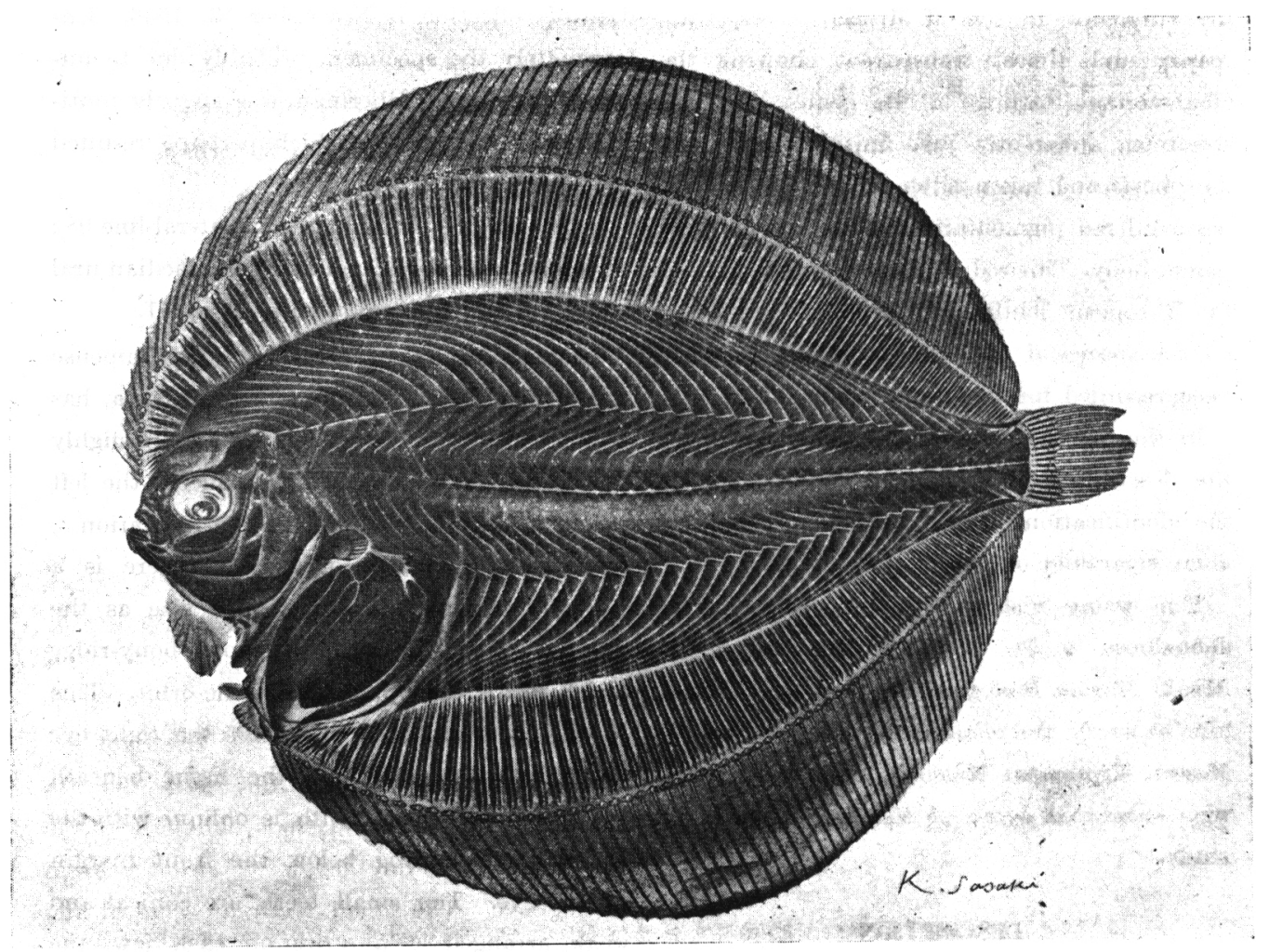

Giant postlarva, probably of Bothus bleekei, $61 \mathrm{~mm}$. in standard length, from Misaki, Japan. 
bony bars, extending bclow the rectum, are tightly attached from each other, and the left one is possessed by a thin bony plate on its ventral margin (only behind the cartilagenous process), the free edge of the plate being well serrated. The pelvic fin-rays are not yet developed. ${ }^{(1)}$ The symmetrical pectoral fin is pedunculated and fan-shape, but the rays are not yet discernible.

The scales are entirely absent.

The lateral line system is well developed only on the left side. The pores on the line are clearly observed from the beginning on the flat-topped anterior curve to the end of the line at the ural plates. The all discernible pores of the mucous canal on the head are shown in Plate; the arrangement of the canal system on the head may not be traced from these pores, but, at least, it is confirmed that the supratemporal branch of the lateral line.

The ural elements of the caudal fin is not clearly visible on this unstained specimen; the ene of the vertebral column is seen running between the two central (ural) elements which seemed to be fairly well fused from each other; the hypural and epiural elements, well defined on their posterior margins but very obscure on their connection to the second last vertebra, are both well separated from the haemal and neural spines respectively of the same vertebra.

The dorsal fin begins on the thmoidal region of the head and in the levelv of upper margin of the eye, but the first inter-neural spine which supports the first ray grows a little behind the ray and directing almost forwards, with a very narrow slit between the spine and the upper profile of the head. The sccond dorsal ray is slightly longer than the third.

The vent is apparently not opener.

Color in formalin solution: except the characteristic jet-black eye, no pigmentation is observed in any extent.

\section{Red pigmented young of Bothus ovalis (REGAN) Figure 1.}

A young, probably just finished the metamorphosis, was collected alive on the shore of Hamana-ko, near the entrance of the lake from the sea, on March 25, 1939. This fish was handed to the writer by Mr. Rerzo SEIshi. The specimen (No. 10035) measures $40 \mathrm{~mm}$. in standard length, 46 in total length, maximum depth of body 30 exclusive of fins, and interorbital space 3 .

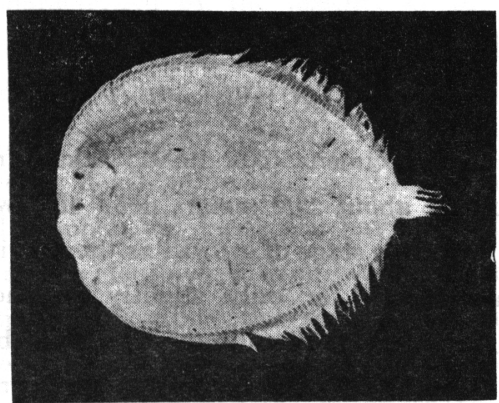

Fig. 1.-Red pigmented young, probably of Bothus ovalis, $40 \mathrm{~mm}$. in standard length, from Hamana-ko, Japan.

D. 89 ; A. 67 ; P. 10 ; vertebrae $10+28=38$, counting the median ural plates as the last: myotomes about 40 .

The specimen is very interesting and remarkable by the possession of red pigments on

(1) By the mutilation on this region of the belly, it is not certain whether the fin-rays are undeveloped or lost. 
the almost transparent body in addition to the ordinary black pigmentation. The red as well as black pigments, however, all fade out about 12 hours after the immersion in formalin solution. The life color notes made by the writer run as follow :

The eyes are characteristically black. The light blackish spots, nearly as large as eye, on the dorsal and anal fins are arranged along the bases of the fins. The light crimson-red spots, smaller than the blackish spots but slightly flattened, occur in a single series, 1) along the both dorsal and ventral contours of the body from near the mouth to the caudal base, 2) along the bases of supporting rays (interneural and interhaemal spines), the upper series running from the brain to the caudal base, and the lower behind the visceral cavity to the caudal base, and, 3) along the free margin of dorsal fin for anterior $2 / 3$ the fin, and along the free margin of the anal fin for anterior half of the fin. The spots on the series mensioned in 2) are lighter than those of others.

\section{5 young fishes of Bothus ovalis}

(REGAN) Figure 2.

The five specimens (No. 10001) taken from the bottom about 200 meters deep off Owase are in the same stage of growth as the previous specimen (10035) or only slightly advanced. These specimens were collected by a trawl-boat before March 1939, and handed to the writer by Prof. Kryomatsu Matsubara.

The measurements in $\mathrm{mm}$. are: $36.0,36.5$, $37.5,38.5$ and 39.5 respectively, in standard length ; 29.2, 27.0, 26.6, 27.0 and 27.5 in maximum depth of body exclusive of the fins; 2.2 , 2.6, 2.4, 2.7, and 2.7. The meristic characters given in the same order are: D. $86,90,92$, 93 and 92 ; A. $65,71,68,69$ and 66 ; P. 10,10, 10,11 and 10 ; vertebrae $10+27,10+27,10+27$, $10+27$ and $10+28$, counting the median ural plates as the last. The myotomes were not

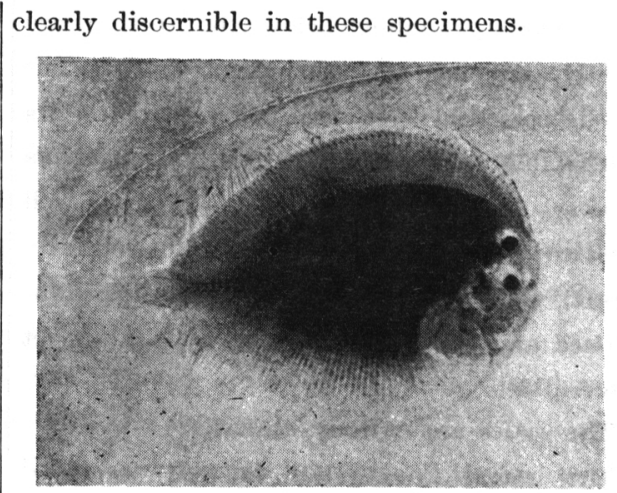

Fig. 2.-A young, probably of Bothus ovalis, $36.5 \mathrm{~mm}$. in standard length, taken off Owase, Japan. The fish, stained and cleared, was photographed on its blind side.

Within these 5 fishes, ranging from 36.0 to $39.5 \mathrm{~mm}$. in standard length, the decrease of relative depth of body with the growth is well observed, the ratio between the standard length and the maximum depth of body being 1.23, $1.31,1.40,1.40$ and 1.43 . In other features, for instance the pelvic bones or caudal (ural) plates, there found no difference by which the stage of the growth is recognized among these specimens.

The general body shape and color pattern of these fishes are well represented by the drawing of Franz (1910, pl. 7, fig. 66) which shows a young $40 \mathrm{~mm}$. long (in total length ?) of Platophrys circularis. Our fishes apparently finished metamophosis not long time before; the pelvic fin is fully developed and all the fin-rays are laid down; the tip of the cleithrum completely retired from the ventral margin of the body.

\section{Two subadult fishes of Bothus ovalis (REGAN)}

These two fishes, measuring 64 and $70 \mathrm{~mm}$ 
(standard length) respectively, were taken from the bottom about 20 meters deep off Miya, Aichi-ken on September 18, 1937. They were caught by a utase-trawl and handed to the writer by Mr. Matsubara.

In the following description the smaller specimen was mentioned first. The depth of body 1.4 and 1.3 measured in the standard length, the length of head 4 and 3.8. The profile of the head is evenly rounded in front of the lower. The diameter of lower eye is 4 and 3.7 measured in the head ; the interorbital width measures 1.5 and 1.4 times the diameter of eye ; the anterior edge of upper eye is about middle of the lower. There is a prominent spine on the snout, and a slight projection below the symphysis of the lower jaw. The maxillary, 3.6 and 4 in the length of head, extends to below the well developed anterior ridge of the orbit. The teeth are more strongly developed on the blind side of jaws; gill-rakers on the lower limb of the first arch number 6 and 7 . The scales are all cycloid on ocular side, except at extreme upper and lower edges of body, where they are rather strongly ctenoid; the pores on the lateral line number 83 and 85. Dorsal 92 and 92. Anal 71 and 71. Pectoral of ocular side, with 10 rays, measures 1.1 and 1.2 times the length of head.

Color in formalin solution; grayish chest-nut brown is the ground color on the head and trunk, marked with darker and pale blotches; a circular ocellus occurs just behind the curve of lateral line, and 3 or 4 less distinct darker blotches on upper and lower halves of body; a diffuse dark blotch, as large as or larger than eye, occurs on the middle of the straight portion of the lateral line. Dorsal and anal fins, dusky along the free margins, have small dark spots in a series; the distal portion of the caudal is dark.

\section{IDENTIFICATION}

\section{Generic}

The giant postlarva at hand, characterized by extremely thin and translucent body, anterior blunt profile, small mouth and jet-black eyes, is undoubtedly identified as a species of genus Bothus. More specifically the specimen falls on the so-called second period postlarval stage defined by KYLE (1913) in the genus.

If, taking precaution on this identification, we consider the fin-formulae alone of the specimen, the genera Arnoglossus, Psettina, and Engyprosopon seem to have some possibility for generic identification. These 3 genera, however, are characterized by the absence of the supratemporal branch of lateral line which, as stated already, was found to exist in our postlarva. In the agreement that the pores and the sclaes develope on the lateral line in nearly equal number, our postlarva, having 98 pores, may not be identified with any of these genera mentioned in which the scale count ranges between 30 and 70. According to KrLE (ibid.), who extensively studied the European forms of Arnoglossus, no postlarva in the genus has such deep dody as our postlarva, and the larvae and youngs of Arnoglossus have always pigmentation of some kind in addition to black eyes. In the light of such evidence, we may be well justified to eliminate these 3 genera from our discussion on generic identification.

The genus Laeops is another form to which the attention should be paid. The genus, with or without supratemporal branch, is charac- 
terized by elongated body and much higher mentioned.

meristic characters, and may be taken out from the present consideration. The small anterior curve of the lateral line in Laeops helps to discriminate our larva irom this genus. Of one species L. parviceps, the postlarva was discovered by $\mathrm{Hr}$ iss and $\mathrm{CHO}^{\circ}$ (1936) which distinctly differs from our postlarva.

The only other generic identification, if possible, would be Parabothus, of which no developement nor metamorphusis has ever becn studicd. According to Normax (1934) the genus is distinguished from Bothus by the interorbital space, spines near the nostrils, dentition and the scalation on the mombrane joining operculum to pectoral arch. These charactcrs, only discernible in the adalt fishes, do not afford the eriteria to distinguish larval specimens. However, so far we can learn from litcrature (mainly Norman (ibid.)), the 3 specics in Parabothus which are reported to live in our water (namely violaceus, coarctes and kiensis) have of larval fish.

higher fin-ray counts, more than 100 in rorsal By the possession of widely separated eyes, a well developed nasal spine and from the fin-ray counts the 2 subadult specimens are also included in the genus Bothus.

\section{Specific}

As already stressed by KYLE (ibid.: 98, footnote) the specific identification of the larval form is bascd mainly on the meristic characters in the group of flatfish now dealt with. But in the attempt of the identification of our specimons, we had to experience a not small amount of uncertainty. This is not because of the raguencss involved in the specimens at hand, but is caused by the lack of the proper identification as wcll as the knowledge of geographical range of the adult forms of the genus Bothus and of other related genera which occur in the watcrs of Japan. Such rircumtance is so often confronted by the students First of all we are convinced to recongnize and 90 in anal, than our postlarva (D. 93, A. two species of Bothus involved in the 3 speci78). This fact will probably climinate the genus mens at hand by the reasons given below. Parahothus from the present discussion. On the When we consider the stage of growth and fin-ray counts further consideration may be the size attained by the fishes, it secms very added in the following section (p. 129). clear that the giant postlarva measuring 61 The red pigmented young (No. 10001) taken $\mathrm{mm}$. in standard length could not be same alive from Hamana-ko is identified as a species species as the 2 sudadult fishes taken off Miya, of Bothus on account of its red coloration (see measuring 64 and $70 \mathrm{~mm}$. respectively. On the Kyle (ibid.: 96)). The five young fishes (No. other hand the red-pigmented specimen (10035) 10001) taken from Owase may be also in the as well as 5 young specimens' (10001) are, withsame genus, because we were unable to find out hesitationf, treatcd as the 2 subadult speciany bodily character distinct from the one just mens, on ths basis of size and growth of stage.(1)

(1) Presumably the metamorphosis in this species takes place at a size, 30 to $40 \mathrm{~mm}$. HubBs (1915) reported symmetrical larva of Bothus myriaster, but not accompanied by description nor comments. 
This identification into 2 species is also sup- fall in one species. ported by the fact that the vertebrae of the giant. postlarva number $10+32=42$, whereas those of other 8 specimens (6 youngs and 2 subadult) number from 37 to 39 ; in the count of anal fin-rays the postlarva (78) is higher than any of other specimens (65-71); of the pores on lateral line the postlarva has 98 and two subadult fishes 83 and 85 respectively. In view of the fact noted above we may reasonably conclude that the large postlarval specimen is specifically different from other 8 specimens which all fall within one species. This well harmonizes with the conclusion, reached by KYIE (il,irl.), that within the same genus (Bothus) the species with lower number of vertebrae and fin-rays metamorphoses as a rule at a small size.

In the attempt of these (supposcdly) 2 specics, we, firstly, need to recall all the species in the genus Bothus which would possibly oceur in our water. Our knowledge on the systematic and the distribution of the species which fall in this (atrogry, however, is entirely depended on the litcrature (mostly Norimax (1934)), because we have no single specimen of the bothid fish referred to the present genus, except those which we are now concerned. In the litcrature we find 6 species which have higher probability to occur in our water; they are mancus, pantherims, bleekeri, myriaster, ovalis and assimilis. Within these forms the last 4 species seem to have, judging from the gengraphical distribution, further higher probability than others. Unfortunately, however, our present knowledge ('an hardly distinguish lleekeri, muriaster and ovalis with each other, and it seems very probable that these species altogether eventually the other hand mancms (85 to 90 ) is much It seems very clear that 2 subadult fishes are neither pantherinus, assimilis nor mancus on account of their feature of scales, and it is more likely that they are ovalis, on the basis of the proportional length of the depth, head and maxillary. The red-pigmented young as well as 5 fishes (10001) are, consequently, also called ovalis.

Theoretically, thus, the postlarva at hand is to be identified as one of either mancus, pantherinus, bleekeri, myriaster or assimilis; in this specific identification of the larval fish before metamorphosis we are urged to depend entirely on the meristic characters for critcria. These characters arc, as described already, clarified in the specimen at hand, but only incompletely knwon in these species listed above, the vertcbrae count known in nome of them and even the fin-ray counts, in the range of variation, not satisfactorily understood. The identification made under such circumstance is conscquently merely tentative.

The conbination of D. 93 and A. 78 possesed by the giant postlarva is not found in any of these 5 spccies now considcred. The larva, however, scems to be close to mancus (I). 98103, A. 76-80) and bleekeri (D. 86-99, A. 6273) than to other 3 specics which have lower counts of dorsal and anal rays. Between these two species, the fin-rays of mancus is too high in dorsal, and the same of bleekri is too low in anal, admitted that the range of the counts given for each species may further extends. The anal-rays of mancus and dorsal-rays of bleekeri are in the range reached by the larva. In the number of scales on the lateral line, on 
fewer than in bleekeri (ca. 100) which seems closer to the larva possessed with 98 pores on the line. In the light of such evidence we may be able to reach final decision that the giant postlarva taken from Misaki is called Bothus bleekeri (REGAN).

As to the species of Parabothus, in which violaceus, coarctes, and kiensis were reported to live in our. water, no study on the developement or metamorphosis have been made; if it happens that the present larva is one of these species, the fin-ray count alone may be taken into consideration. However, all these species have, as already stated on p. 128, more than 100 dorsal and 90 anal -rays (only kiensis reported to have 85 by KamoHara (1938) and 87 anal rays by Tanaka (1918)). These fin-ray counts show much less prodability of identification thah any of species of Bothus considered above.

\section{BIBLIOGRAPHY}

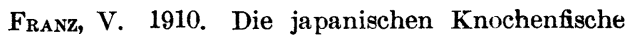
der Sammlungen Haberer und Doflein. Alh. Bayer. Akad. Wiss., 2 cl., suppl. 4 : 1-135, pls. 1-11. figs. 1-7.

Hubis, C CARL L. 1915. Flounders and soles from Japan collected by the United States Bureau Fisheries Steamer "Albatross" in 1906. Pro. U. S. Nat. Mus., $48: 449-496$, pls. $25-27$.

Hubbs, Carl L. and Chu, Yuanting T. 1934, Asiatic fishes (Diproprion and Laeops) having a greatly elongated dorsal ray in very large postlarva. Occ. Pap. Mus. Zool. Univ. of Michigan, 299 : 1-7, pls. 1-2.

Kamohara, Toshiji 1938. On the off-shore bottom-fishes of Prov. Tosa, Shikoku. Tokyo: 186, figs. 1-43.

KYLE, H HRRY M. 1913. Flat-fishes (Heterosomata). Rep. Danish Ocean. Exped. 1908-10, 2: 1-150, figs. $1-30$, pls. i-iv.

Norman, J. R. 1934. A systematic monograph of the Flatfishes (Heterosomata), 1, British Museum i-v, 1-459, figs. 1-317.

$\mathrm{T}_{\text {ANaKa, }}$, Shigko. 1918. 12 new species of fishes of Japan (in Japanese). Zool. Mag. 30: 223-227: 